\title{
THE PATHOGENESIS OF HALLUX RIGIDUS
}

\author{
MICHAEL J. McMASTER \\ From the University Department of Orthopaedic Surgery, Edinburgh
}

\begin{abstract}
The clinical, radiological and pathological features of hallux rigidus affecting nine toes (in seven patients) are described. Characteristic chondral and osteochondral lesions are seen to occur at a specific site on the metatarsal head, and account for the limitation of dorsiflexion but relatively unrestricted plantarflexion typical of hallux rigidus. Radiologically these lesions are often missed because they are mainly cartilaginous and are later obscured by secondary degenerative changes. Histological evidence indicates a traumatic aetiology and a mechanism of injury is suggested.
\end{abstract}

Hallux rigidus is characterised by painful restriction of dorsiflexion of the great toe due to degenerative arthritis of the metatarsophalangeal joint. It is often found in the adolescent or young adult, in whom degenerative joint disease does not usually occur without an underlying predisposing factor.

The aetiology has long been debated. Many authors have suggested that an anatomical abnormality in the foot, such as a dorsal hyperextension of the first metatarsal (Lambrinudi 1938; Jack 1940), an abnormally long first metatarsal (Nilsonne 1930; McMurray 1936; Bonney and Macnab 1952), or pronation of the forefoot (Jansen 1921), may be predisposing causes. Kessel and Bonney (1958), reporting on hallux rigidus in the adolescent, found two patients with osteochondritis dissecans of the first metatarsal head but were unable to say whether this was a primary or secondary feature. Goodfellow (1966) reported three adolescent patients with osteochondritis dissecans and suggested that this was the most common although unrecognised cause of hallux rigidus developing in later life.

The purpose of this paper is to draw attention to certain characteristic radiological and pathological features occurring in the younger patient with hallux rigidus-features which are probably common but usually unrecognised-and suggest a pathogenesis of the condition.

\section{CLINICAL MATERIAL}

The clinical and radiological features of seven patients with hallux rigidus in nine great toes are summarised in Table I.

Age and sex. There were five females and two males whose ages ranged from twelve to thirty-three years with an average age of twenty-one years.

Symptoms. All patients presented with increasing pain in the first metatarsophalangeal joint which had been present from a few weeks to several years. One patient, a girl aged fourteen (Case 1), could date the symptoms from a specific injury sustained a few weeks earlier when she stubbed her great toe in the gymnasium. The remaining six patients could not remember any specific injury. In all cases the pain was aggravated by walking and relieved by rest. Four patients complained of stiffness after rest. The right great toe was affected in five patients and the left in four. Two patients (Cases 3 and 5) had bilateral involvement.

Findings. On examination of the affected first metatarsophalangeal joints all appeared normal except for a slight swelling around the joint. All affected joints were found to be tender over the dorsum, and there was a marked painful restriction of dorsiflexion. Plantarflexion was also often limited but to a much less degree. Apart from these findings the feet were normal.

\section{RADIOGRAPHIC FEATURES}

The earliest radiological evidence of abnormality in the first metatarsal head was seen in the fourteen-year-old girl (Case 1) who had stubbed her toe. An anteroposterior radiograph of the toe showed a chip fracture at the distal end of the proximal phalanx and a small subchondral defec: in the dome of the metatarsal head (Fig. 1). A lateral radiograph showed that the actual site of this subchondral defect lay just dorsal to the apex of the dome of the metatarsal head, and adjacent to the dorsal lip of the base of the proximal phalanx (Fig. 2). This patient was followed for six years, during which the subchondral defect in the metatarsal head developed a sclerosed margin and the metatarsal head became slightly flattened (Figs. 3 and 4).

Radiographs of the affected joints of the remaining six patients all showed lesions affecting the same area of the dome of the first metatarsal head. Three metatarsal heads showed an island of subchondral bone surrounded

M. J. McMaster, F.R.C.S., Senior Lecturer and Consultant Orthopaedic Surgeon, University Department of Orthopaedic Surgery, Clinical Research Unit, Princess Margaret Rose Orthopaedic Hospital, Fairmilehead, Edinburgh EH10 7ED, Scotland. 
Table I. Clinical and radiological findings in the first metatarsophalangeal joint (seven patients, nine joints)

\begin{tabular}{|c|c|c|c|c|c|c|c|c|c|c|}
\hline $\begin{array}{c}\text { Case } \\
\text { number }\end{array}$ & $\begin{array}{c}\text { Age } \\
\text { (years) }\end{array}$ & Sex & Occupation & Side & $\begin{array}{l}\text { History } \\
\text { of injury }\end{array}$ & Symptoms & $\begin{array}{l}\text { Duration of } \\
\text { symptoms }\end{array}$ & Movements & $\begin{array}{l}\text { Radiological } \\
\text { appearance of } \\
\text { first metatarsal } \\
\text { head }\end{array}$ & Treatment \\
\hline 1 & 14 & Female & Schoolgirl & Right & Yes & Pain & 1 month & $\begin{array}{l}\text { Dorsiflexion } 10^{\circ} \\
\text { plantarflexion } 60^{\circ}\end{array}$ & $\begin{array}{l}\text { Small subchondral } \\
\text { defect. Joint other- } \\
\text { wise normal }\end{array}$ & Observation \\
\hline 2 & 20 & Female & Nurse & Left & None & $\begin{array}{l}\text { Pain and } \\
\text { stiffness }\end{array}$ & 4 months & $\begin{array}{l}\text { All movements } \\
\text { painful }\end{array}$ & $\begin{array}{l}\text { Osteochondritis } \\
\text { dissecans }\end{array}$ & Arthrodesis \\
\hline 3 & 33 & Male & Postman & Right & None & $\begin{array}{l}\text { Pain and } \\
\text { stiffness }\end{array}$ & 2 years & $\begin{array}{l}\text { No dorsiflexion } \\
\text { in either joint } \\
\text { but full } \\
\text { plantarflexion }\end{array}$ & $\begin{array}{l}\text { Osteochondritis } \\
\text { dissecans in both }\end{array}$ & Observation \\
\hline & & & & Left & None & $\begin{array}{l}\text { Pain and } \\
\text { stiffness }\end{array}$ & 2 years & & & Observation \\
\hline 4 & 12 & Female & Schoolgirl & Right & None & Pain & 1 year & $\begin{array}{l}\text { Dorsiffexion } 10^{\circ}, \\
\text { plantarflexion } 20^{\circ}\end{array}$ & $\begin{array}{l}\text { Loose body lying } \\
\text { under metatarsal } \\
\text { head }\end{array}$ & $\begin{array}{l}\text { Removal of } \\
\text { loose body }\end{array}$ \\
\hline 5 & 20 & Female & Clerk & Right & None & $\begin{array}{l}\text { Pain and } \\
\text { stiffness }\end{array}$ & 1 year & $\begin{array}{l}\text { Dorsiflexion } 20^{\circ} \\
\text { plantarflexion } 40^{\circ}\end{array}$ & $\begin{array}{l}\text { Subchondral defect } \\
\text { and early degenera- } \\
\text { tive changes }\end{array}$ & Arthrodesis \\
\hline 6 & 25 & Male & Labourer & Right & None & $\begin{array}{l}\text { Pain and } \\
\text { stiffness }\end{array}$ & Many years & $\begin{array}{l}\text { No dorsiflexion; } \\
\text { plantarflexion } \\
\text { restricted in both }\end{array}$ & $\begin{array}{l}\text { Subchondral defect } \\
\text { and moderate to } \\
\text { severe degenerative } \\
\text { changes in both }\end{array}$ & Arthrodesis \\
\hline & & & & Left & None & $\begin{array}{l}\text { Pain and } \\
\text { stiffness }\end{array}$ & Many years & & & Arthrodesis \\
\hline 7 & 23 & Female & Clerk & Left & None & Pain & 2 years & $\begin{array}{l}\text { Dorsiflexion } 10^{\circ}, \\
\text { plantarflexion } 45^{\circ}\end{array}$ & $\begin{array}{l}\text { Subchondral defect } \\
\text { and moderate } \\
\text { degenerative } \\
\text { changes }\end{array}$ & Arthrodesis \\
\hline
\end{tabular}

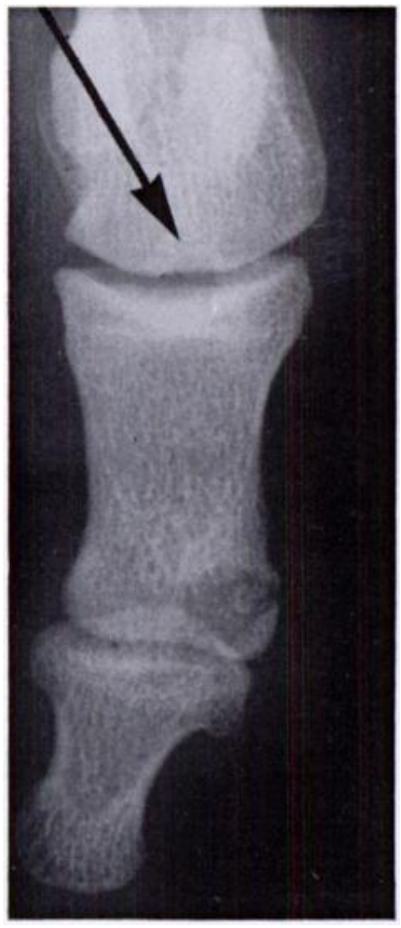

Fig. 1

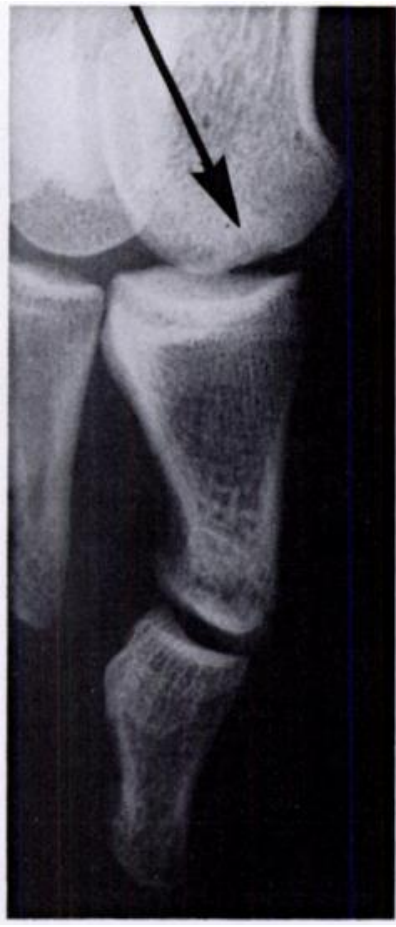

Fig. 2

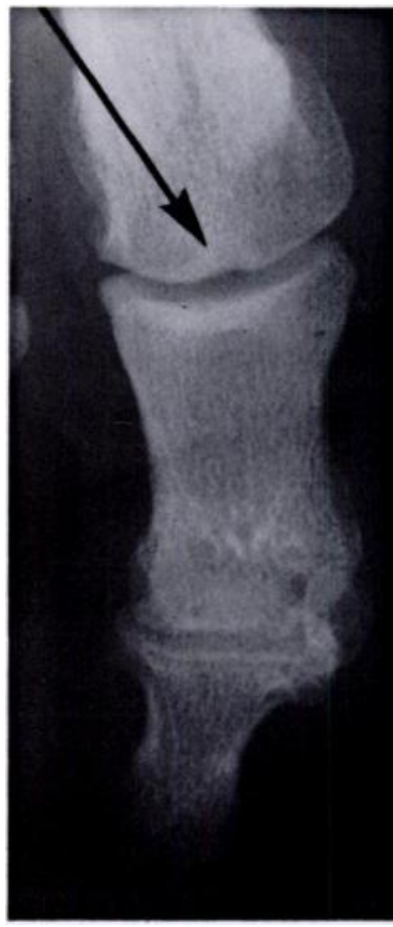

Fig. 3

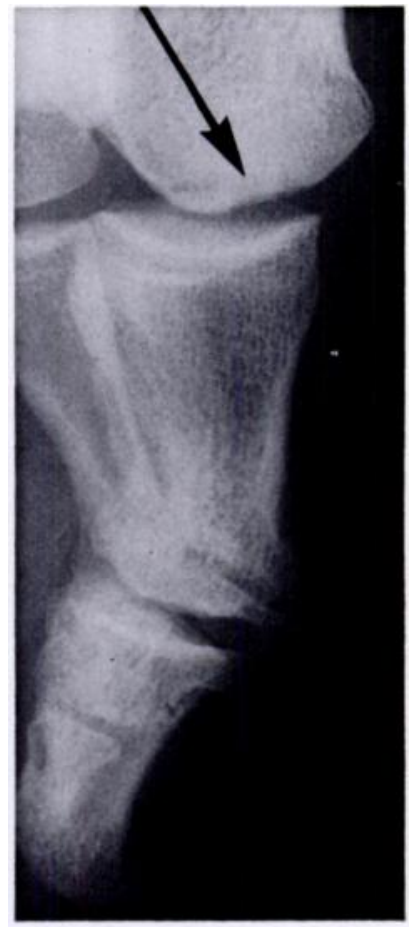

Fig. 4

Case 1. Figure 1-Anteroposterior radiograph showing a small subchondral defect (arrowed) in the dome of the first metatarsal head and also a chip fracture at the distal end of the proximal phalanx. Figure 2-Lateral radiograph showing that the subchondral defect (arrowed) lies opposite the dorsal lip of the base of the proximal phalanx. Figures 3 and 4-Anteroposterior and lateral radiographs six years later showing that the subchondral defect (arrowed) has become demarcated by a zone of sclerosis and the metatarsal head slightly flattened. 


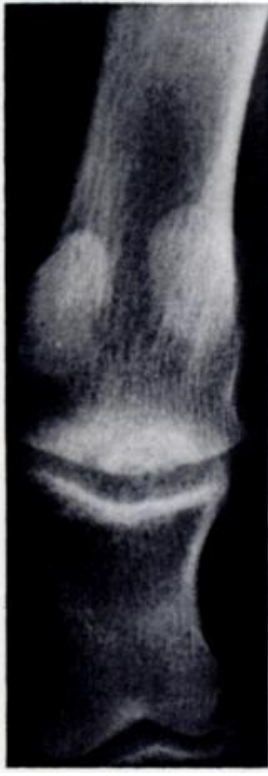

Fig. 5

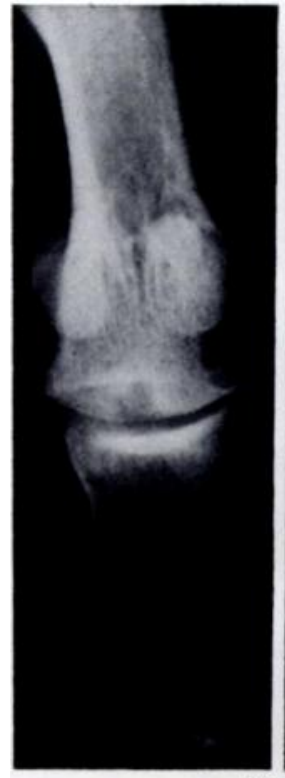

Fig. 6

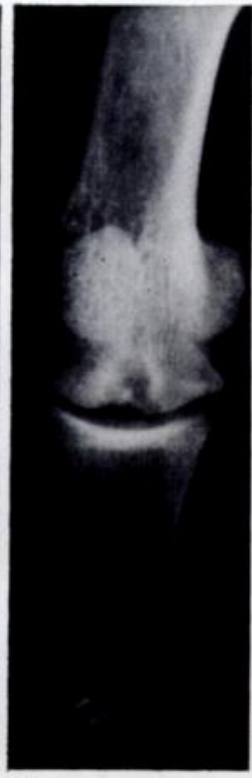

Figure 5-Case 2. Anteroposterior radiograph showing typical osteochondritis dissecans in the dome of the first metatarsal head. The separating fragment of bone is set in an island of rarefaction surrounded by a zone of sclerosis. Figure 6-Case 3. Anteroposterior radiograph showing symmetrical osteochondritis dissecans lesions in both first metatarsal heads. Small flecks of bone are set in lytic areas surrounded by zones of sclerosis.

by an area of rarefaction lying within a zone of sclerosis, suggesting osteochondritis dissecans (Figs. 5 and 6). However the most common radiological picture, seen in five metatarsal heads (Figs. 8, 11 and 14), was of a subchondral bony defect surrounded by a zone of sclerosis with no evidence of a separate fragment of bone.

Several patients who had symptoms for some time also had radiological evidence of degenerative changes affecting the joint. These degenerative changes, consisting of narrowing of the joint space, peripheral osteophytes and flattening of the metatarsal head, made the lesion in the metatarsal head more difficult to recognise, and now gave the radiological appearance of hallux rigidus (Fig. 11, right toe).

Bilateral symmetrical lesions were seen in the first metatarsal heads of two patients (Cases 3 and 6), and in each patient the bilateral lesions had a remarkably similar radiological appearance (Figs. 6 and 11).

One patient (Case 4) demonstrated a loose body in the joint, lying under the head of the metatarsal and seen clearly only in an oblique radiographic projection (Fig. 7).

Apart from these pathological changes in the first metatarsophalangeal joint, all the feet were radiologically normal.

\section{PATHOLOGICAL FINDINGS}

Six first metatarsophalangeal joints in five patients were sufficiently symptomatic to warrant operation. Five joints were arthrodesed and from one a loose body was removed. At the time of operation the pathological findings were noted and the heads of three metatarsals, which had been resected to allow fusion of the joint, were sent for histological preparation.

Gross pathological changes. The macroscopic appearance was remarkably similar in all cases. The basic lesion consisted of a single, partly separated flap of articular cartilage which constantly lay between the apex of the dome and the dorsal margin of the metatarsal head (Figs. 9, 12 and 15). The flap was approximately 5 by 5 millimetres in size and lay in a crater of similar dimensions in the metatarsal head. In all cases the flap of articular cartilage had separated to a greater or lesser degree on its dorsal aspect, but remained attached by an isthmus of intact articular cartilage on its plantar aspect leading towards the centre of the dome of the metatarsal head. The separated edge of the flap and the adjacent margin of the crater were often ragged and fragmented, but the remainder of the articular surface of the metatarsal head appeared normal.

In one patient (Case 4) the fragment had separated completely from the "classical" site and the resulting crater in the metatarsal head had healed as an irregular defect. The loose body was found lying beneath the metatarsal head, partly adhèrent to the joint capsule (Fig. 7). The cartilaginous component of the loose body appeared to have grown in the synovial fluid and was now larger than the site from which it had originated.

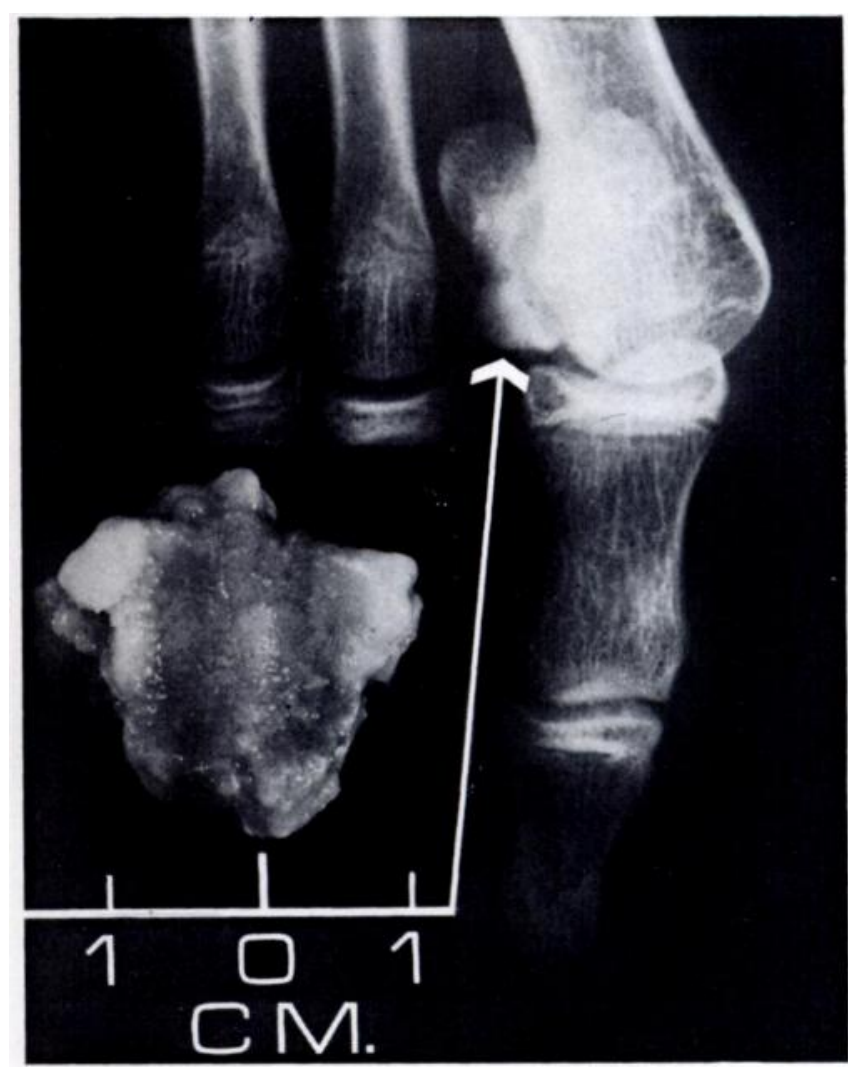

Fig. 7

Case 4. Oblique radiograph showing a loose body (inset) lying under the first metatarsal head. 


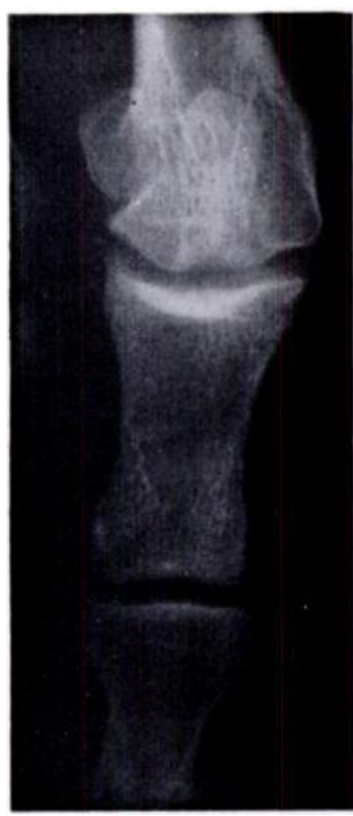

Fig. 8

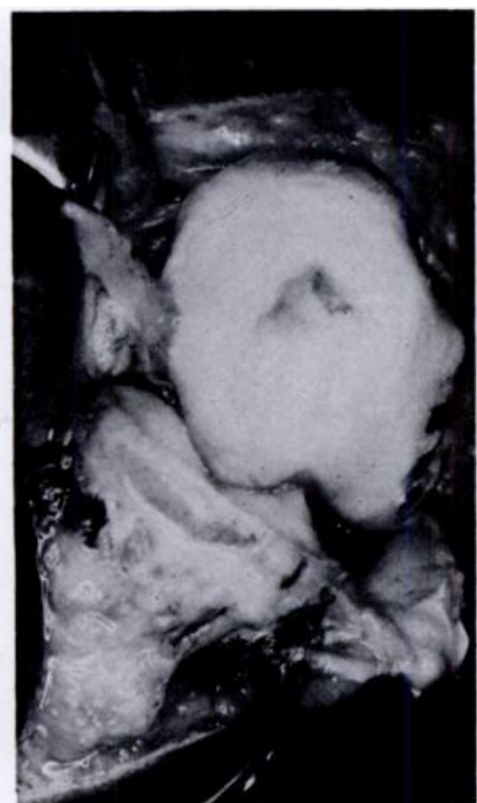

Fig. 9

At operation the first metatarsophalangeal joint was exposed through a dorsomedial incision and the capsule opened longitudinally. Blue dye was placed on the dorsal lip of the base of the proximal phalanx and the joint rearticulated. The joint was then extended from the neutral position and the area of contact of the dorsal lip of the proximal phalanx on the head of the metatarsal

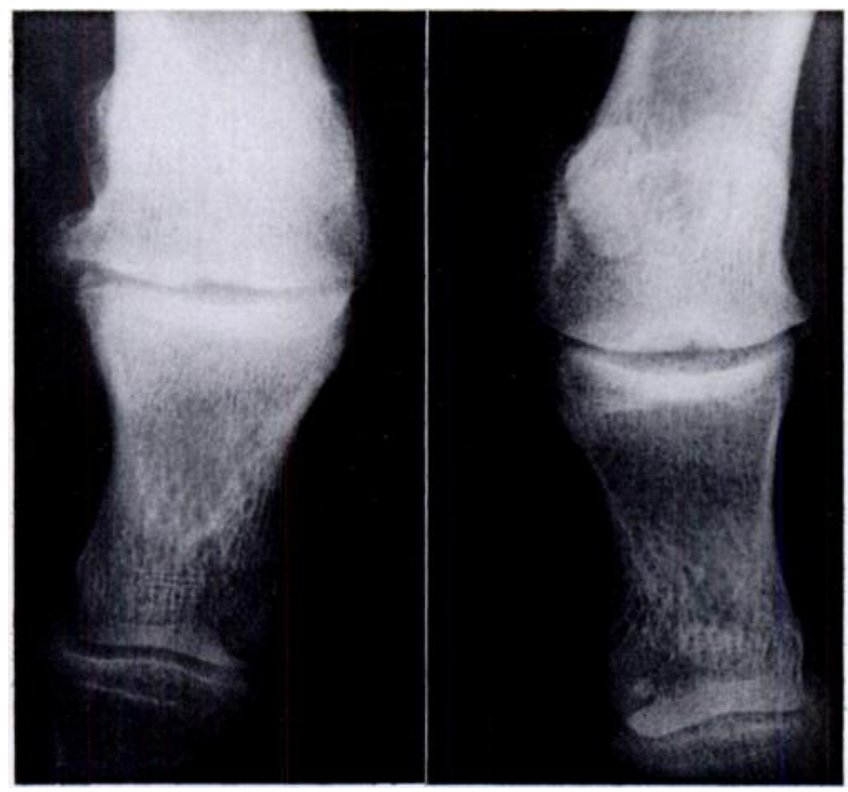

Fig. 11

Case 6. Figure 11-Anteroposterior radiograph showing symmetrical subchondral defects in the domes of both metatarsal heads. On the right the defect is almost obscured by degenerative changes and now has the appearance of a hallux rigidus. Figure 12-Head-on view of the right first metatarsal head at operation. The chondral lesion is seen at the "classical" site on the metatarsal head. Figure 13-Histological sagittal section through the metatarsal head, showing the separating fragment with its remaining plantar attachment. A few fragments of calcified cartilage are seen on the undersurface of the flap. The base of the defect in the metatarsal head is filled with granulation tissue (Von Kossa's stain).

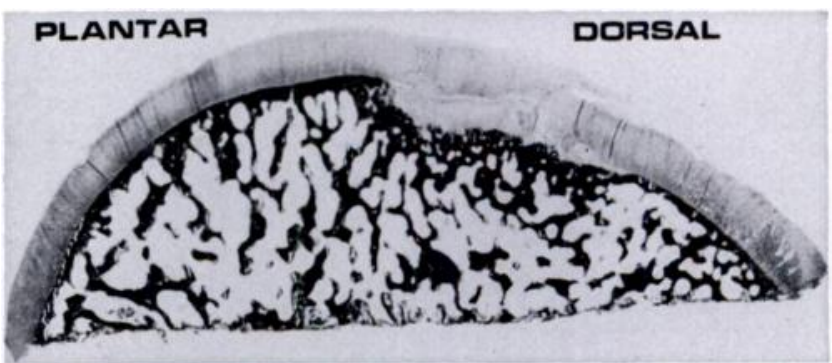

Fig. 10

Case 5. Figure 8-Anteroposterior radiograph of the first metatarsal showing a subchondral defect in the dome of the metatarsal head. Figure 9-Head-on view of the first metatarsal head at operation through a dorsomedial incision. A partially separated flap of articular cartilage is seen at the "classical" site on the metatarsal head. Figure 10-Histological sagittal section through the metatarsal head, showing a cleavage lesion in the articular cartilage producing a cartilaginous flap with a plantar attachment (Von Kossa's stain). Note the step in the subchondral bone beneath the flap.

was outlined by dye. In the neutral position, the "classical" site for the lesion on the metatarsal head lay directly beneath the dorsal lip of the proximal phalanx, and as the joint was extended the dorsal lip moved across this area. However, on flexing the joint a few degrees from the neutral position the "classical" site was uncovered.

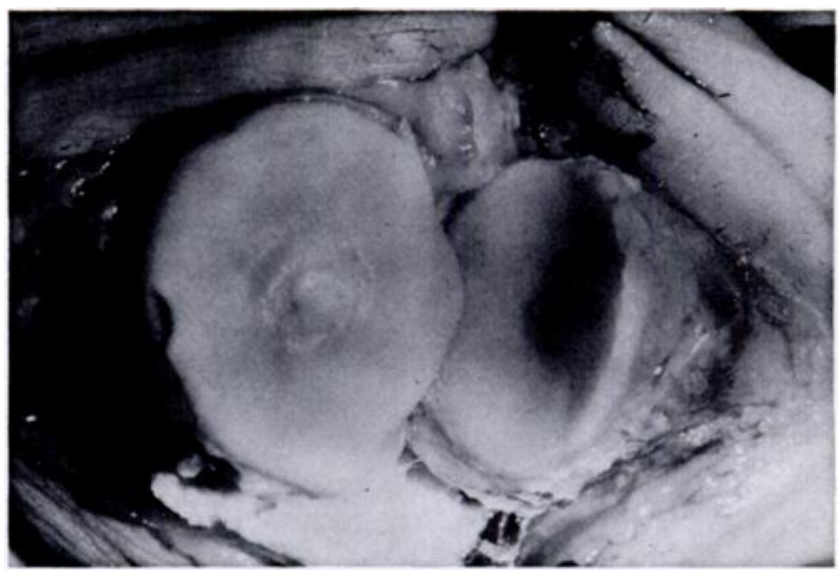

Fig. 12

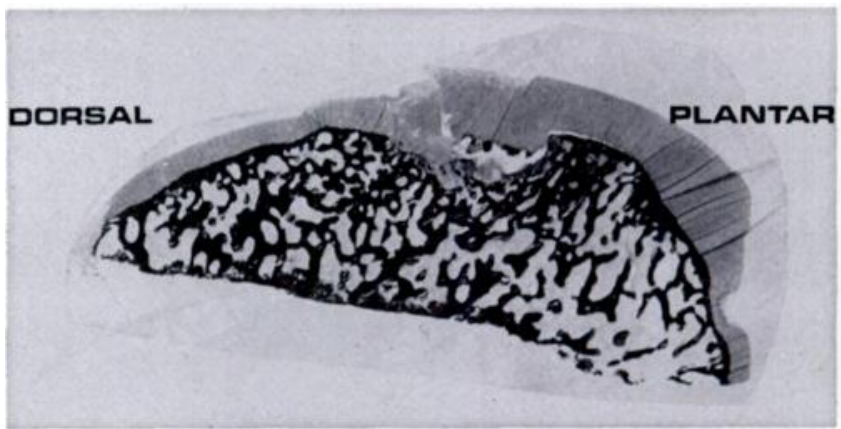

Fig. 13 


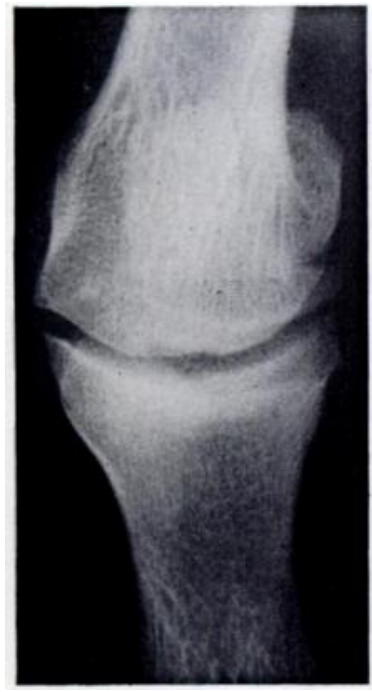

Fig. 14

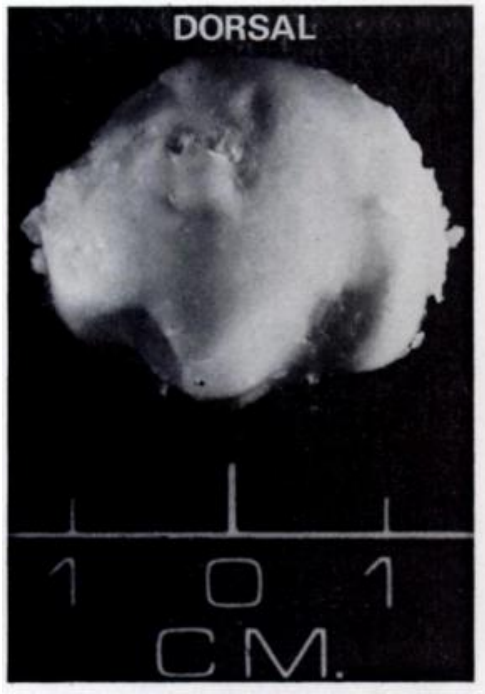

Fig. 15

Microscopic appearances. Three of the resected first metatarsal heads (Cases 5,6 and 7) were sectioned sagittally through the centre of the lesions and prepared for histological examination. The sections from these three metatarsal heads were all remarkably similar (Figs. 10, 13 and 16): each showed a cleavage lesion in the articular cartilage, separating off a flap from the dorsal aspect but still retaining an intact isthmus of the cartilage on the volar aspect directed towards the centre of the dome of the metatarsal head. The articular cartilage in the separated flap was degenerate but the surrounding cartilage on the metatarsal head was relatively normal. Attached to the undersurface of the flap in Case 6 were a few fragments of calcified tissue which were thought to be calcified cartilage rather than subchondral bone (Fig. 13). The base of the defect contained fibrous granulation tissue and the deeper layers showed reactive new bone formation. More deeply still the bony trabeculae were thickened and irregular, consistent with repair of an old injury. In Case 5 (Fig. 10) there was a definite step in the subchondral bone, as if the bone had been impacted by a blow. More advanced degenerative changes appearing as cystic spaces were seen in the bone beneath the cartilaginous flap in Case 7 (Fig. 16).

\section{DISCUSSION}

This study has shown that the radiological finding of osteochondritis dissecans can occur in the first metatarsal head of patients presenting with hallux rigidus (Figs. 5 and 6). Similar radiological findings have been described by Goodfellow (1966).

A more common microscopic finding, however, is of a cleavage lesion in the articular cartilage of the first metatarsal head without any attached subchondral bone (Figs. 10 and 16). Such a lesion could better be

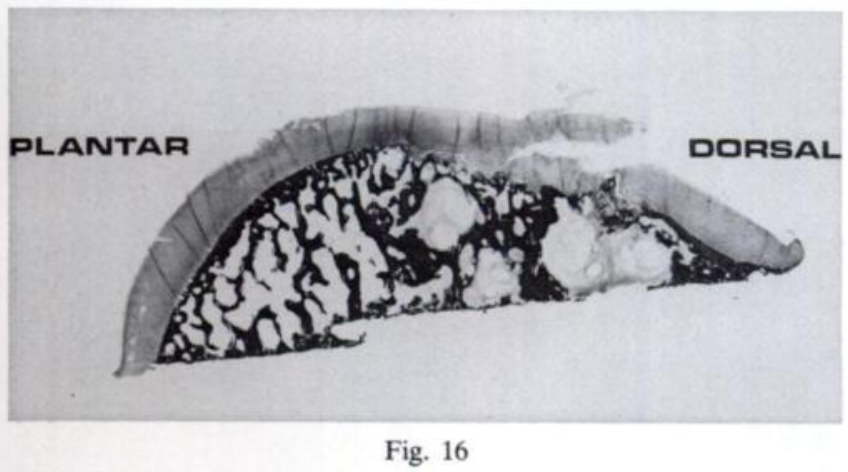

Case 7. Figure 14-Anteroposterior radiograph of the first metatarsal showing a shallow subchondral defect in the dome of the metatarsal head and moderate degenerative changes in the joint. Figure 15-Head-on view of the resected first metatarsal head showing the chondral lesion at the "classical" site. Figure 16-Histological sagittal section through the metatarsal head showing the separating flap of articular cartilage. Degenerative cysts are present in the bone beneath the flap (Von Kossa's stain).

described as a "chondritis dissecans" and appears radiologically as a small depression in the dome of the metatarsal (Figs. 1 and 2). This radiological appearance is easily missed and the true diagnosis overlooked. A zone of sclerosis indicating repair in the surrounding bone of the metatarsal head may make the lesion a little more obvious (Figs. 3 and 8), but it is soon obscured by secondary degenerative changes (Figs. 11 and 14). The radiological picture is now that of hallux rigidus.

Trauma, either acute or chronic, has always been emphasised as a cause of hallux rigidus. If the great toe were to be stubbed, with sudden forced extension and axial compression, the dorsal lip of the base of the proximal phalanx would impinge on the convex metatarsal head at a point between the apex of the dome and the dorsal margin (Fig. 17). Such a tangential force applied as a single severe incident or as repetitive

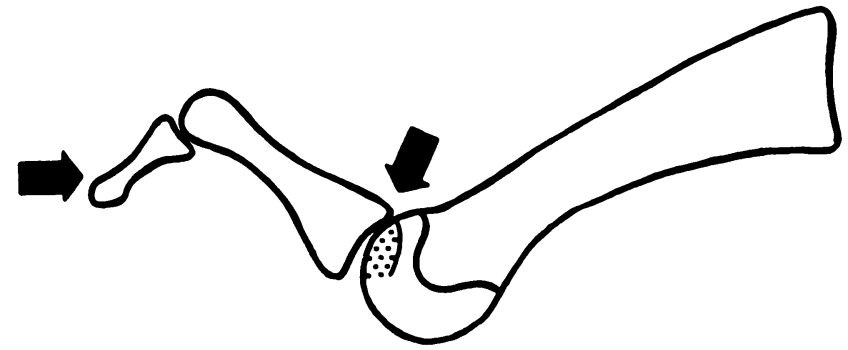

Fig. 17

Diagram of a sagittal section of the first metatarsophalangeal joint, showing the mechanism by which the chondral or osteochondral lesion is produced at the "classical" site on the metatarsal head.

unrecognised minor incidents could produce either an osteochondral fracture or a cartilaginous cleavage lesion in the metatarsal head. One patient (Case 1) who sustained such an injury showed radiological evidence of a defect in the metatarsal head at a point just dorsal to the apex of the dome and adjacent to the dorsal lip of the proximal phalanx (Figs. 1 and 2). This patient, who 
previously had no symptoms, developed hallux rigidus (Fig. 3). Pathological examination has shown that characteristic chondral lesions do occur on the metatarsal head of patients presenting with hallux rigidus. The interesting feature of these lesions is that they all occur at exactly the same site on the metatarsal head, between the apex of the dome and the dorsal margin, and all have an intact attachment directed towards the centre of the metatarsal head and therefore on the opposite side to the suggested direction of force (Figs. 9, 12 and 15). Smillie (1960) stated that repeated minor injury to a specific area of articular cartilage tends to produce a lesion whose remaining attachment is on the side opposite to the direction of force which produced it. The histological preparations (Figs. 10,13 and 16) show that the lesion in the metatarsal head is almost entirely cartilaginous, and the changes in the subchondral bone suggest that they are secondary to increased stress or trauma. One patient showed a definite step in the subchondral bone, suggesting an impacting blow from without (Fig. 10). There is no evidence of avascular necrosis of bone.

Any of the relatively minor anatomical abnormalities in the foot suggested by other authors (Jansen 1921; Nilsonne 1930; McMurray 1936; Lambrinudi 1938; Jack 1940; Bonney and Macnab 1952) as causative factors for hallux rigidus will predispose the great toe to increased stress or trauma and hence give rise to the characteristic lesion on the metatarsal head.
Frieberg's infraction or osteochondritis dissecans of the second metatarsal head differs from osteochondritis dissecans of the first metatarsal in that the separating osteochondral fragment consists of a much larger proportion of the total joint surface and is therefore more easily seen radiologically. Both lesions are very similar in that the osteochondral fragment separates first from the dorsal aspect of the metatarsal head and an isthmus of cartilage remains intact on the plantar aspect (Figs. 10,13 and 16). Eventually the isthmus may give way, releasing a loose body into the joint (Fig. 7).

Tenderness over the dorsum of the first metatarsophalangeal joint is easily explained by the site of the lesion towards the dorsum of the metatarsal head. The experiment with blue dye has shown that with dorsiflexion the dorsal lip of the proximal phalanx moves across the lesion on the metatarsal head, presumably so causing pain and hence muscle spasm which limits further dorsiflexion. Plantarflexion tends to uncover the lesion and is therefore not so painful or restricted. Under general anaesthesia the range of dorsiflexion is much greater once muscle action is eliminated.

In conclusion it is suggested that hallux rigidus in the younger patient is the result of trauma, either acute or chronic, producing a characteristic lesion on the metatarsal head. This lesion is often not recognised radiologically because it is mainly cartilaginous, and is later obscured by secondary degenerative changes.

\section{REFERENCES}

Bonney, G., and Macnab, I. (1952) Hallux valgus and hallux rigidus. A critical survey of operative results. Journal of Bone and Joint Surgery, 34-B, 366-385.

Goodfellow, J. (1966) Aetiology of hallux rigidus. Proceedings of the Royal Society of Medicine, 59, 821-824.

Jack, E. A. (1940) The aetiology of hallux rigidus. British Journal of Surgery, 27, 492-497.

Jansen, M. (1921) Hallux valgus, rigidus and malleus. Journal of Orthopaedic Surgery, 3, 87-90.

Kessel, L., and Bonney, G. (1958) Hallux rigidus in the adolescent. Journal of Bone and Joint Surgery, 40-B, 668-673.

Lambrinudi, C. (1938) Metatarsus primus elevatus. Proceedings of the Royal Society of Medicine, 31, 1273.

McMurray, T. P. (1936) Treatment of hallux valgus and rigidus. British Medical Journal, 2, 218-221.

Nilsonne, H. (1930) Hallux rigidus and its treatment. Acta Orthopaedica Scandinavica, 1, 295-303.

Smillie, I. S. (1960) Osteochondritis Dissecans, p. 60. Edinburgh and London: E. \& S. Livingstone Ltd. 